\title{
Balkanologie
}

Balkanologie Revue d'études pluridisciplinaires

Vol. VIII, $n^{\circ} 1$ | 2004

Volume VIII Numéro 1

\section{Bruneau (Michel), Diasporas et espaces transnationaux}

Paris : Anthropos (Collection « Villes-Géographie »), 2004, 249 pages

Taline Ter Minassian

\section{CpenEdition}

Journals

Édition électronique

URL : http://journals.openedition.org/balkanologie/2074

DOI : 10.4000/balkanologie.2074

ISSN : 1965-0582

Éditeur

Association française d'études sur les Balkans (Afebalk)

Édition imprimée

Date de publication : 1 juin 2004

ISSN : 1279-7952

Référence électronique

Taline Ter Minassian, «Bruneau (Michel), Diasporas et espaces transnationaux », Balkanologie [En ligne], Vol. VIII, $n^{\circ} 1$ | 2004, mis en ligne le 21 janvier 2010, consulté le 17 décembre 2020. URL : http:// journals.openedition.org/balkanologie/2074; DOI : https://doi.org/10.4000/balkanologie.2074

Ce document a été généré automatiquement le 17 décembre 2020.

(c) Tous droits réservés 


\section{Bruneau (Michel), Diasporas et espaces transnationaux}

Paris : Anthropos (Collection « Villes-Géographie »), 2004, 249 pages

Taline Ter Minassian

\section{RÉFÉRENCE}

Bruneau (Michel), Diasporas et espaces transnationaux, Paris : Anthropos (Collection «Villes-Géographie »), 2004, 249 p.

1 Qu'est-ce qu'une diaspora? Un mot grec signifiant l'état de dispersion ou de dissémination d'un peuple. Une notion historico-religieuse remontant à la nuit des temps décrivant l'exil et la dispersion du peuple juif. Une migration massive et forcée consécutive à une guerre ou une révolution. La notion de diaspora est apparue dans le champ des sciences sociales au cours de la décennie de 1970-1980, intéressant désormais historiens, sociologues et géographes. Selon Michel Bruneau,

à cause de son origine et de son modèle initial, le terme de diaspora relève des domaines religieux et politique, et d'une migration connotée négativement, qu'elles qu'en soient les causes (désastre, famine, châtiment...). La diaspora suppose également la référence à une communauté homogène dans la durée, à une "nation ", et à un territoire d'origine sacralisé. Elle s'est donc constituée dans une double tension temporelle et spatiale : la tension vers un ailleurs originel (notion d'exil à partir d'un territoire d'origine) et celle vers un futur idéalisé, vers une "Terre Promise", qui peut être par exemple, le Nouveau Monde.

2 Fondée sur le paradigme de la diaspora juive, la définition géographique de la diaspora s'énonce comme une "dispersion, alimentée par des exodes successifs, d'une entité ethnoculturelle solidement constituée préalablement à son essaimage » (Pierre George), une situation qui correspond parfaitement aux cas de quelques diasporas constituées plus récemment comme la diaspora arménienne, chinoise ou libanaise. Audelà de cette définition simple qui manifeste la pleine appartenance des diasporas au champ de l'espace géographique, les géographes ont tendance à se scinder entre une interprétation maximaliste de la diaspora, vue comme un avatar de la globalisation, et 
une interprétation restrictive soulignant la nécessité de critères précis. En se fondant sur une abondante production bibliographique, Michel Bruneau présente une typologie distinguant quatre types essentiels de diasporas: diasporas de type entrepreneurial comme les diasporas chinoise, indienne et libanaise ; diasporas où le facteur religieux souvent associé à une langue, est prédominant comme les diasporas juive, grecque, arménienne, assyro-chaldéenne; diasporas politiques lorsque le «territoire d'origine est dominé par une puissance étrangère et que la principale aspiration des populations diasporées est la création d'un État-nation » comme la diaspora palestinienne dont la principale matrice est la nakba de 1948. Un dernier type de diaspora s'organise autour d'un pôle racial et culturel comme la diaspora noire dont l'originalité réside dans l'absence de filiation directe avec les territoires d'origine et par son ampleur continentale. "Le brassage et le nivellement de la traite transatlantique a eu pour fonction de faire disparaître ces éléments de la mémoire, de faire disparaitre les familles également, en en prenant en compte que des individus». La difficulté de la représentation cartographique des diasporas tient entre autres à la dimension intercontinentale du phénomène où l'on distingue des espaces émetteurs et récepteurs de diasporas. Notion encore incertaine à laquelle Michel Bruneau associe volontiers la formule de "peuple-monde », la diaspora est cependant une source d'indétermination, voire de confusion dans le champ scientifique. Michel Bruneau propose un bilan ordonné des recherches entreprises au cours des deux dernières décennies dans cet ouvrage destiné aux étudiants comme aux spécialistes. On trouvera dans les sept chapitres qui forment l'architecture de l'ouvrage, les thèmes géographiques intéressant l'espace et la territorialité des diasporas. Voici une dizaine d'années, Michel Bruneau avait coordonné un ouvrage intitulé Diaspora (Montpellier: GIP Reclus, 1995) dans lequel il énumérait un certain nombre de thèmes prometteurs intéressant la quasitotalité des diasporas : l'espace économique de la diaspora étudié à différentes échelles, les circulations migratoires des diasporas, les édifices religieux et les réseaux institutionnels qui les relient, le rôle des États d'accueil, la territorialité des diasporas dans ses relations avec le territoire d'origine et enfin l'inscription des diasporas dans les grandes villes. Ces thèmes sont développés de façon plus systématique à partir d'une bibliographie récente. Fondé sur une démarche souvent typologique, l'ouvrage rencontre les écueils de cette méthodologie et ne les évite pas toujours en procédant ponctuellement à des généralisations abusives. On peut douter par exemple du rôle attribué à l'Église apostolique arménienne dans la structuration contemporaine de la diaspora arménienne. De même, la tentative de catégorisation des événements "catastrophiques" à l'origine même des diasporas, distinguant les tentatives d'extermination de masse, les désastres et la traite et l'esclavage n'est pas très convaincante. Néanmoins, la cartographie ainsi que les nombreux encarts consacrés à des points spécifiques - par exemple les Grecs pontiques et leurs monastères - font de cet ouvrage un fort utile ouvrage de référence. 


\section{AUTEURS}

TALINE TER MINASSIAN

fr 